\title{
Study and Design of Microstrip Antenna
}

\author{
Saransh Kumar Singh ${ }^{1}$, Mihir Mayank ${ }^{2}$ \\ ${ }^{1,2}$ Department of E\&TC \\ Bharti Vidhyapeeth Deemed University College of Engineering, Pune, Maharashtra, India
}

\begin{abstract}
This paper is about the theoretical and practical study of Microstrip antennas. In the paper we have simulated the results of two rectangular microstrip patch antenna and fabricated them into a single patch that works on multi frequency operations. For the same we have taken two antennas of frequency $9 \mathrm{GHz}$ and $5.67 \mathrm{GHz}$ and impedance matching is done at 50ohm. The feed is coaxial feed with corner excitation The antennas after being rearranged with corner excitation is investigated for operating frequency, return loss and radiation pattern. The rearranged structure shows reduction in resonant frequency. The pattern of radiation seems to be almost same. The frequency of the rearranged antenna is perceived to have increased from before. The whole simulation work is done on HFSS software.
\end{abstract}

Keywords: gain, returnloss, bandwidth

\section{Introduction}

Micro strip antennas are small and lightweight in structure. They can easily be fabricated and moved from one place to another. They are quite handy due to their small size and better gain. They can be used at higher bandwidth if used in arrays. Microstrip antennas are available in many shapes and sizes like rectangular, circular, elliptical etc or they can be fabricated in any regular shapes. The antenna comprises of a metal patch that is mounted on the insulating dielectric substrate. If the antenna is fabricated on a mounted spaced substrate then the bandwidth is widened and it has a rugged structure. These antennas are quite hardy and efficient to use because of their rugged nature and wide range of applications in various fields such as in military operations, mounted on various vehicles, in satellite communications, and mobile operations in the communication fields.

For this paper we have designed two separate antennas working at $9 \mathrm{GHz}$ (X band) and $5.67 \mathrm{GHz}$ respectively using the HFSS software. Then they are connected to each other after being rearranged with corner excitation. After the corner excitation the new fabricated antenna works on frequencies in range of $5.77 \mathrm{GHz}, 7.32 \mathrm{GHz}$ and $7.80 \mathrm{GHz}$ with increasing frequency ratio.

Thus this fabricated antenna can be used for wide variety of multi frequency operations in the real time world.

\section{Theoretical Consideration}

The figure (a) shows that the first antenna with the frequency of $9 \mathrm{GHz}$. The dimensions are $12.8 \mathrm{~mm}$ and 9.8 $\mathrm{mm}$ respectively. The feed provided to the antenna is a coaxial cable feed of $1 \mathrm{~mm}$. the impedance matching of the feed is $50 \mathrm{ohms}$ from the point of feed provided to the antenna.

The figure (b) shows the second antenna that works at the frequency of $5.67 \mathrm{GHz}$. The feed provided to the antenna is from the edge of the antenna.
The last figure shows the depiction of the rearrangement of the modified patch of the two central frequency antennas. The two conventional single frequency antennas are connected with corner excitation. The new antenna shows the characteristics of Multi frequency antenna.

The feeding is provided at the connecting point of the two single frequency conventional antennas.

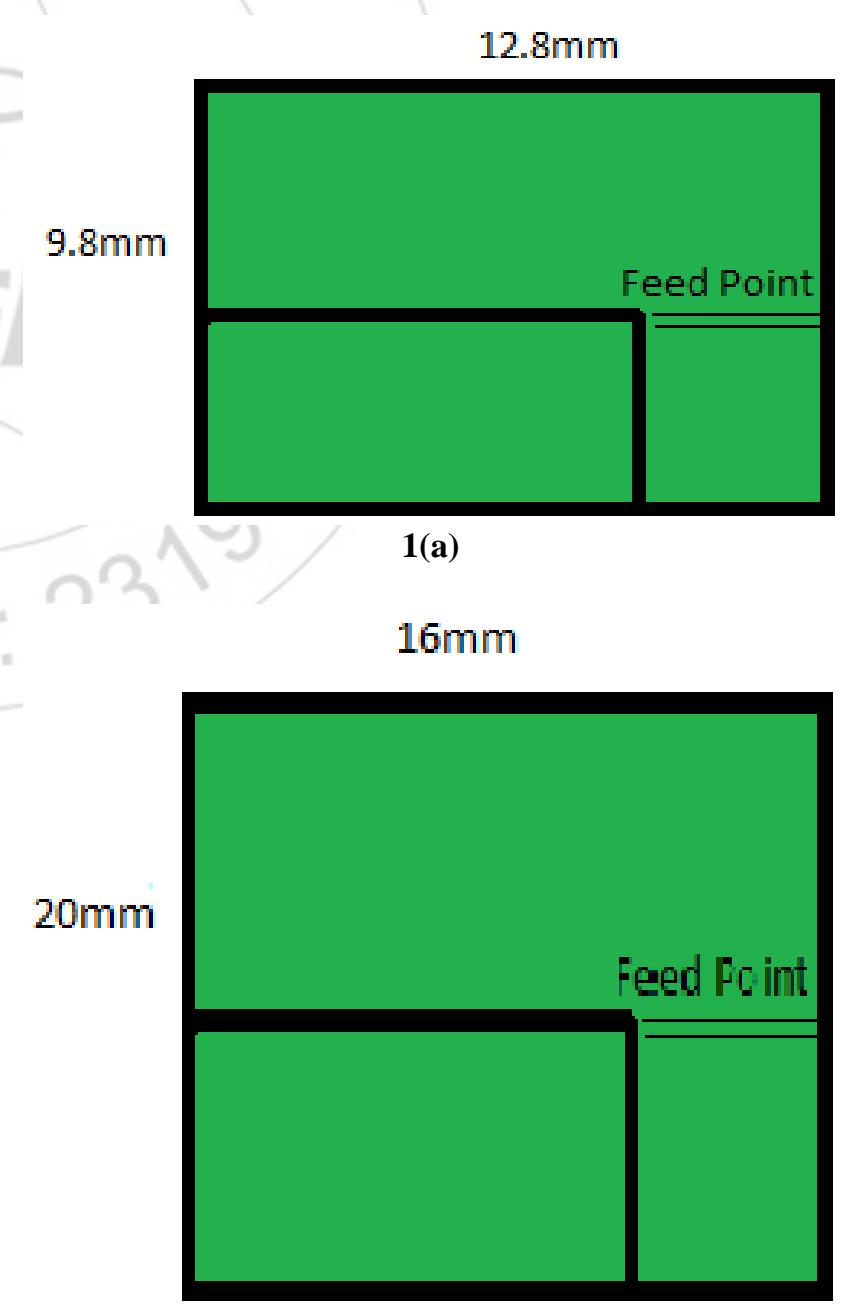

1(b) 


\section{International Journal of Science and Research (IJSR) \\ ISSN (Online): 2319-7064}

Index Copernicus Value (2013): 6.14 | Impact Factor (2015): 6.391

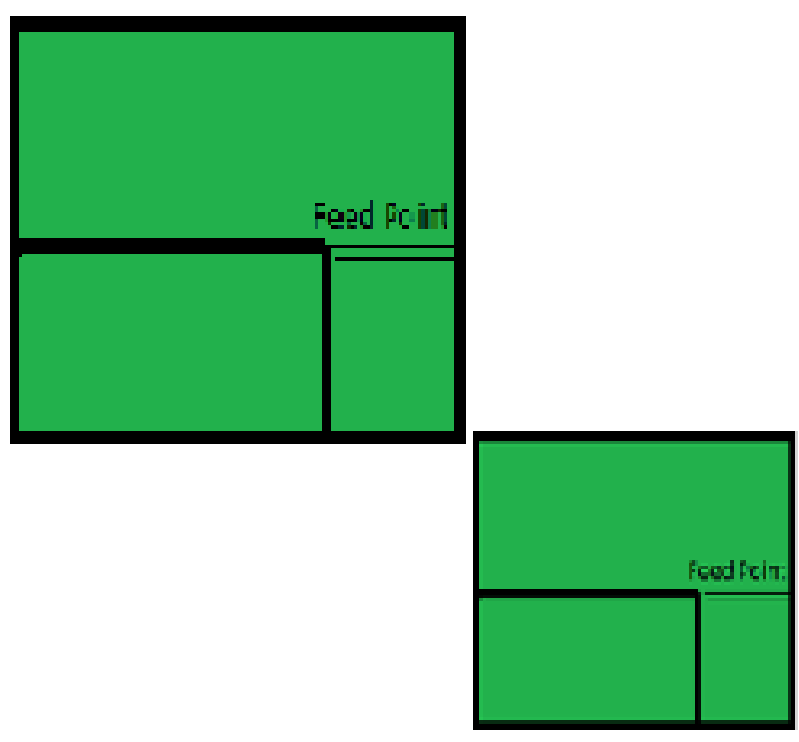

1(c)

Figure 1: (a) Antenna 1 configuration (b) Antenna 2 configuration (c) Modified Antenna 3

A. The formulas used to calculate width, effective dielectric constant, effective length, length extension and actual length are calculated using the equation 1, 2, 3, 4, Respectively.[1]

An initial guess at the patch width:

$$
\text { [1] } W=\frac{c_{o}}{2 f_{r}} \sqrt{\frac{2}{\epsilon_{r}+1}}, c_{o} \text { is speed of light }
$$

Find effective parameters:

Get patch length:

$$
\begin{aligned}
& \text { [2] } \epsilon_{\text {reff }}=\frac{\epsilon_{r}+1}{2}+\frac{\epsilon_{r}-1}{2}\left[1+12 \frac{h}{W}\right]^{-1 / 2}, W / h \\
& \text { [3] } \frac{\Delta L}{h}=0.412 \frac{\left(\epsilon_{\text {reff }}+0.3\right)\left(\frac{W}{h}+0.264\right)}{\left(\epsilon_{\text {reff }}-0.258\right)\left(\frac{W}{h}+0.8\right)}
\end{aligned}
$$

$$
\text { [4] } L=\frac{c_{o}}{2 f_{r} \sqrt{\epsilon_{\text {reff }}}}-2 \Delta L
$$

\section{B. Dimension of Antennas}

The dimension of antennas used for the design has been calculated using above formulas which has been tabulated below.

Table. 1 Dimension for the antenna 1 designed for $9 \mathrm{GHz}$

\begin{tabular}{|l|l|}
\hline Parameter & Value \\
\hline Length of the radiator patch $(\mathrm{L})$ & $9.8 \mathrm{~mm}$ \\
\hline Width of the radiator patch $(\mathrm{W})$ & $12.8 \mathrm{~mm}$ \\
\hline Relative dielectric constant $\left(\varepsilon_{\mathrm{r}}\right)$ & 2.4 \\
\hline Thickness of substrate $(\mathrm{h})$ & $1.6 \mathrm{~mm}$ \\
\hline Resonant frequency $\left(\mathrm{f}_{0}\right)$ & $9 \mathrm{GHz}$ \\
\hline
\end{tabular}

Table. 2 Dimension for the antenna 2 designed for 5.67 $\mathrm{GHz}$

\begin{tabular}{|l|l|}
\hline Parameter & Value \\
\hline Length of the radiator patch $(\mathrm{L})$ & $16 \mathrm{~mm}$ \\
\hline Width of the radiator patch $(\mathrm{W})$ & $20 \mathrm{~mm}$ \\
\hline Relative dielectric constant $\left(\varepsilon_{\mathrm{r}}\right)$ & 2.4 \\
\hline Thickness of substrate $(\mathrm{h})$ & $1.6 \mathrm{~mm}$ \\
\hline Resonant frequency $\left(\mathrm{f}_{0}\right)$ & $5.67 \mathrm{~Hz}$ \\
\hline
\end{tabular}

\section{Result and Discussion}

A. The design of the reference structure for $5.67 \mathrm{GHz}$ is given below. Similarly the other antenna of $9 \mathrm{GHz}$ is designed and connected to the conventional single frequency antenna already simulated. This plot for the given patch is drawn by the simulation using HFSS software.
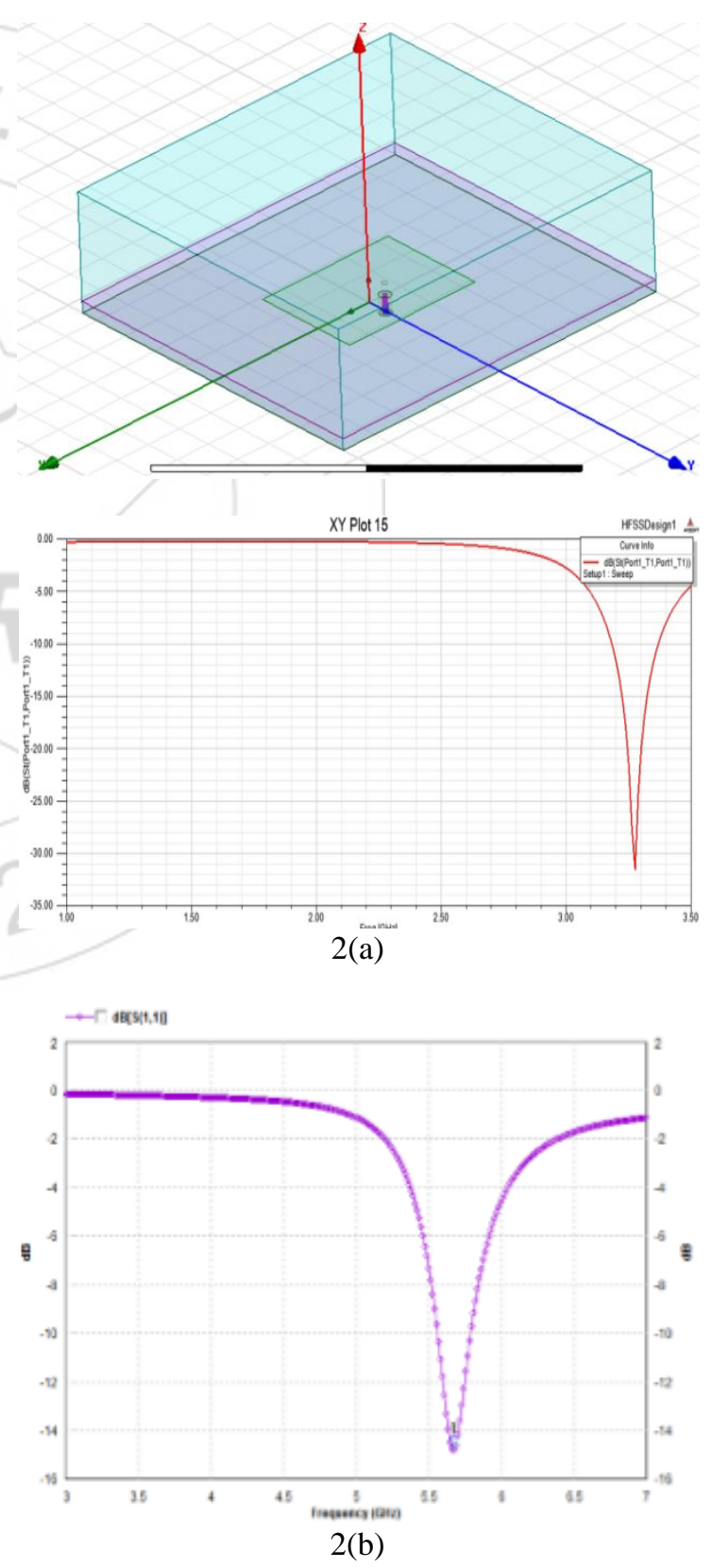

Figure 2: (a) Return loss plot for antenna 1 (b) Return loss plot for antenna 2

\section{Volume 5 Issue 5, May 2016}




\section{International Journal of Science and Research (IJSR) \\ ISSN (Online): 2319-7064}

Index Copernicus Value (2013): 6.14 | Impact Factor (2015): 6.391

The simulation of the results show the return loss of antenna 1 of $5.67 \mathrm{GHz}$ at $-16 \mathrm{~dB}$. Its bandwidth is 227 $\mathrm{MHz}$. the second antenna at $9 \mathrm{GHz}$ shows a return loss of $28.1 \mathrm{~dB}$ with a frequency bandwidth of $620 \mathrm{MHz}$.

Thus according to the above results we might conclude that the two conventional single frequency antennas are properly functioning and operational within the operation range as specified by IEEE standards.

\section{B. Radiation Pattern}

The figures depicted below show the radiation pattern for the conventional and the modified microstrip patch antennas which are simulated at their resonant frequency. The radiation patterns for conventional antenna 1 and antenna 2 are given in figure 3 .

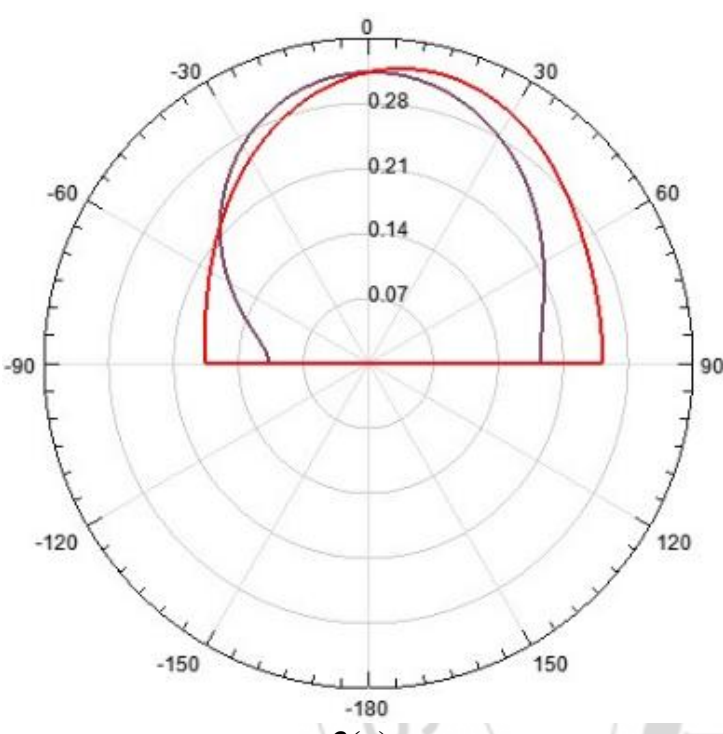

(a)

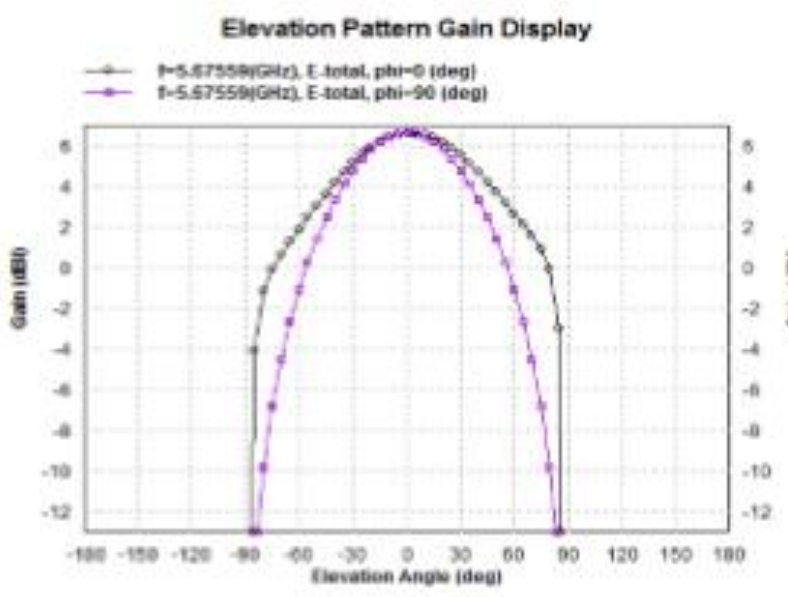

(b)

Figure 3: (a) Radiation pattern for antenna 1 at $5.67 \mathrm{GHz}$ (b) Radiation pattern for antenna 2 at $9 \mathrm{GHz}$

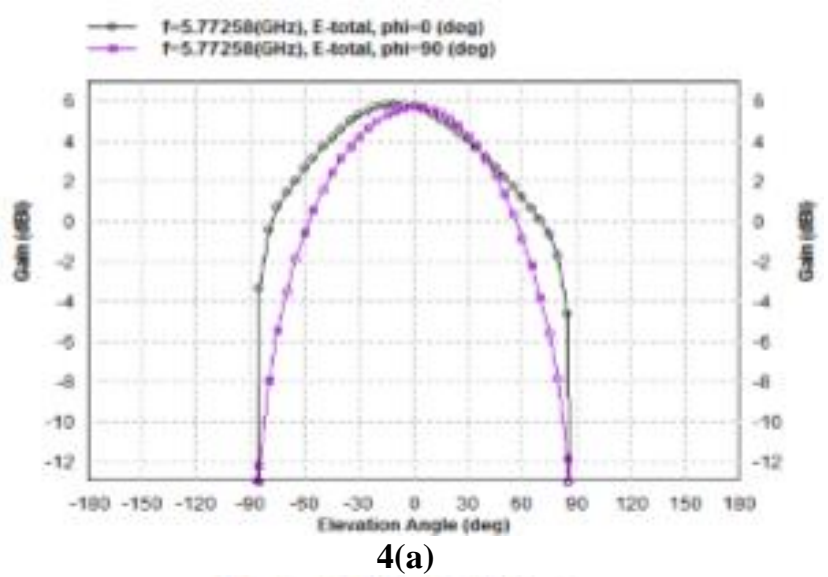

Elevation Pattern Gain Display

$\rightarrow+732 \mathrm{~m} 6 \mid \mathrm{GH}$, E-total, phi=0 (deg) t-7.32776iGHz), E total, phi-90 (deg)

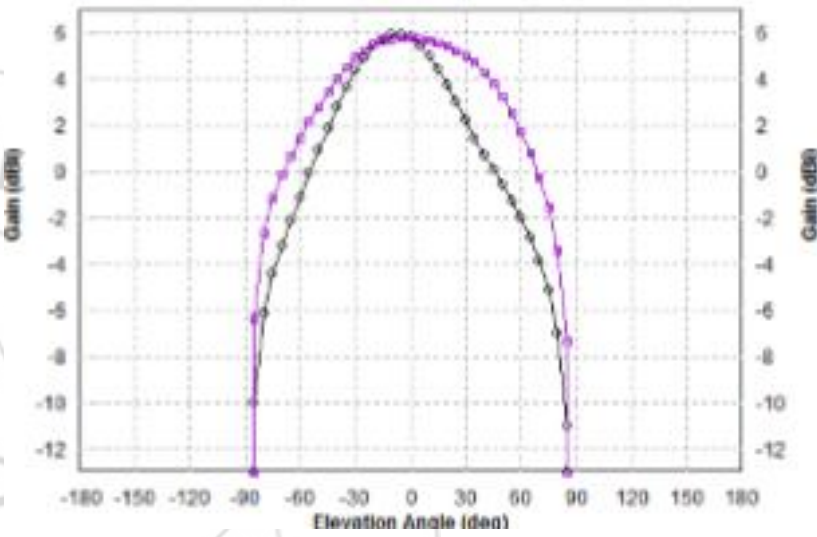

4(b)

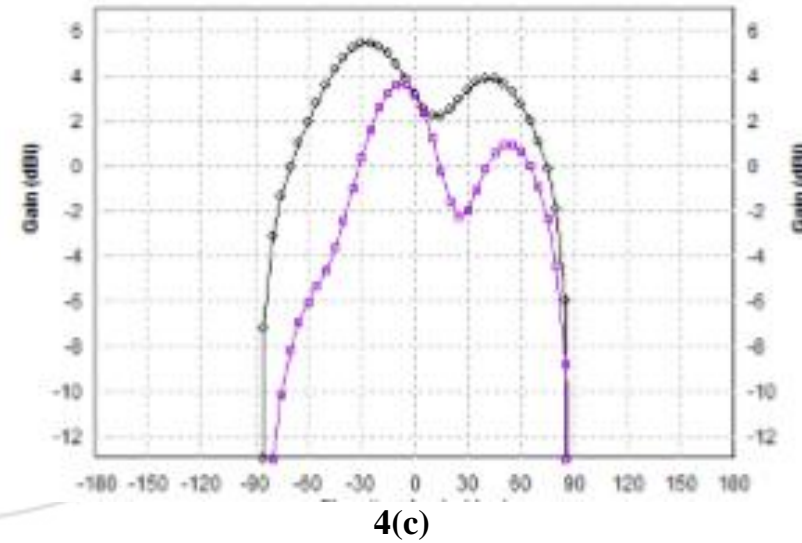

Figure 4: (a) Radiation pattern for antenna 3 at $5.77 \mathrm{GHz}$

(b) Radiation pattern for antenna 3 at $7.32 \mathrm{GHz}$ (c) Radiation pattern for antenna 3 at $7.80 \mathrm{GHz}$

The two dimensional radiation pattern of the modified antenna 3 is shown in the figure 4 . The beam width according to the above figures is 1000, 1020, 1180 for frequencies at $5.77 \mathrm{GHz}, 7.32 \mathrm{GHz}$ and $7.80 \mathrm{GHz}$ respectively. The respective absolute gain is $5.79 \mathrm{~dB}$, $5.86 \mathrm{~dB}$ and $5.38 \mathrm{~dB}$. The above radiation patterns show similar variation of radiation performance of antenna which is desirable for multi-frequency.

\section{Conclusion}

Two micro strip antennas at single frequency are design at $9 \mathrm{GHz}$ and $5.67 \mathrm{GHz}$. A multi-frequency antenna is 


\section{International Journal of Science and Research (IJSR) \\ ISSN (Online): 2319-7064}

Index Copernicus Value (2013): 6.14 | Impact Factor (2015): 6.391

improvised by connecting two antennas with corner excitation.. The new antenna works in the range of three frequency operation at $5.77 \mathrm{GHz}, 7.32 \mathrm{GHz}$ and $7.80 \mathrm{GHz}$ with consistency of radiation patterns. The antenna is used for wireless communication system applications.

\section{Acknowledgement}

We would like thank our Faculty Mr. Deepak kr. Ray \& Prof NT Markad for their kind support and guidance. We also like to extend our support to TEQIP-II for funding the software ANSys HFSS.

\section{References}

[1] "Welcome to antennas 101" by Louis E. Frenzel, "Electronic Design" 2008

[2] Bancroft, R. Microstrip and Printed Antenna Design Noble Publishing 2004, chapter 2-3

[3] Lo, Y.T., Solomon D. and Richards, W.F. "Theory and Experiment on Microstrip Antennas," IEEE Transactions on Antennas and Propagation, AP-27, 1979 pp. 137-149.

[4] "PIFA - The Planar Inverted-F Antenna".

[5] Iulian Rosu. "PIFA - Planar Inverted F Antenna".

[6] Taga, T. Tsunekawa, K. and Saski, A., "Antennas for Detachable Mobile Radio Units," Review of the ECL, NTT, Japan, Vol. 35, No.1, January 1987, pp. 59-65.

[7] "Inverted-F Antenna (IFA)" at antenna-theory.com

[8] Di Nallo, C.; Faraone, A., "Multiband 